\title{
In-Situ Micro Compression Testing on Polycrystalline Model Materials and Potential Nuclear Fusion Candidate Materials
}

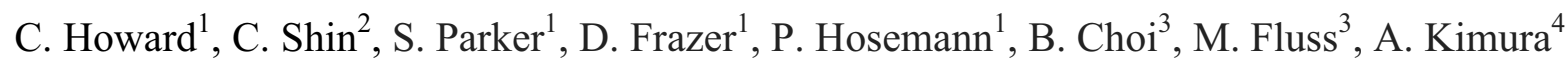 \\ ${ }^{1}$ UC Berkeley, Berkeley, California, 94720 \\ ${ }^{2}$ Korea Atomic Energy Research Institute \\ ${ }^{3}$ Lawrence Livermore National Laboratory \\ ${ }^{4}$ Institute of Advanced Energy, Kyoto University, Uji, Kyoto, Japan
}

Ultra small scale mechanical testing has been made possible due to the development of focused ion beam instruments and nanoindentation equipment. In 2001, M. Uchic introduced micro compression testing to the scientific community as a means to examine size effects in micrometer sized single crystal compression specimens using a truncated Berkovich tip in a conventional nanoindenter [1,2,3]. Since that many basic science papers were published where mechanical materials properties such as yield strength and elastic modulus are characterized. However, now with the availability of these techniques and an initial understanding of the basic science, engineering applications such as reactor and Spallation source materials analysis can benefit from it [4,5]. Small scale samples provide many benefits including reduction in the amount of nuclear material necessary to obtain information about a material's mechanical properties, availability of ion beam and reactor irradiated materials for mechanical testing, fundamental insight in structure-property relationships, increased statistics on less sample material, and cost reductions. However, the number of strength determining features that dominate the behavior of engineering materials remains to be determined. For example, what the minimum number of grains and grain boundaries are in order to obtain bulk properties of a material. In addition the effect of dose and implanted ion species on micromechanical tests needs to be thoroughly evaluated.

An experimental study of ultra fine grained, UHP copper was performed in order to help answer this question via in situ compression using a Hysitron Pi 85 Picoindenter after fabricating pillars with an FEI Focused Ion Beam microscope with cross-sectional sizes between approximately $0.25 \mu \mathrm{m} \times 0.25 \mu \mathrm{m}$ and $5 \mu \mathrm{m} \times 5 \mu \mathrm{m}$. Micro compression testing was conducted on this series of specimens. An image of a micro pillar and a size comparison of yield strength are shown in Figure 1.

Small grain, UHP copper was chosen as a baseline material because its mechanical properties have been studied extensively $[6,7]$. However additional scaling studies were also performed on stainless steel and ODS alloys. The primary advantages of in situ testing are higher precision focusing and alignment of the punch tip and test specimen pillar due to the high resolution of both the electron and ion beams that provide views along all three axes as well as the ability to take real time videos of each compression test.

A parallel study involving two potential candidates for fusion reactors, $\mathrm{K} 3$ oxide dispersed strengthened (ODS) steel and a $\mathrm{Fe} 14 \% \mathrm{Cr}$ stainless steel (SS) alloy, which were both ion beam irradiated is currently taking place in collaboration with LLNL. The specimens were irradiated utilizing a triple ion beam $(\mathrm{H}$, He and heavy ions) and post irradiation micro compression testing was performed. It was determined that the K3-ODS sample showed no significant strength changes due to the ion beam irradiation. 
Investigation of the $\mathrm{Fe} 14 \% \mathrm{Cr}$ sample is in progress. However it was found that sudden large slip takes place in the irradiated samples. Pillars of cross-sectional sizes between $1 \mu \mathrm{m} \times 1 \mu \mathrm{m}$ and $1.6 \mu \mathrm{m} \times 1.6$ $\mu \mathrm{m}$ were fabricated and compressed.

\section{References}

[1] M. D. Uchic et al, Mater. Res. Soc. Symp. Proc. 753, BB1.4 (2003).

[2] M. D. Uchic et al, Science 305, 986 (2004).

[3] M. D. Uchic and D. M. Dimiduk, Mater. Sci. Eng., A 400, 268 (2005).

[4] P. Hosemann et al, J. Nucl. Mat.375 (2008) 135-143

[5] P. Hosemann et al, J. Nucl. Mat. 417, (2011) 274-278

[6] X.H. Chen, L. Lu, and K. Lu, Scripta Materialia 64 (2011) 311-314.

[7] W.J. Kim, K.E. Lee, and S.-H. Choi, Materials Science and Engineering A 506 (2009) 71-79.
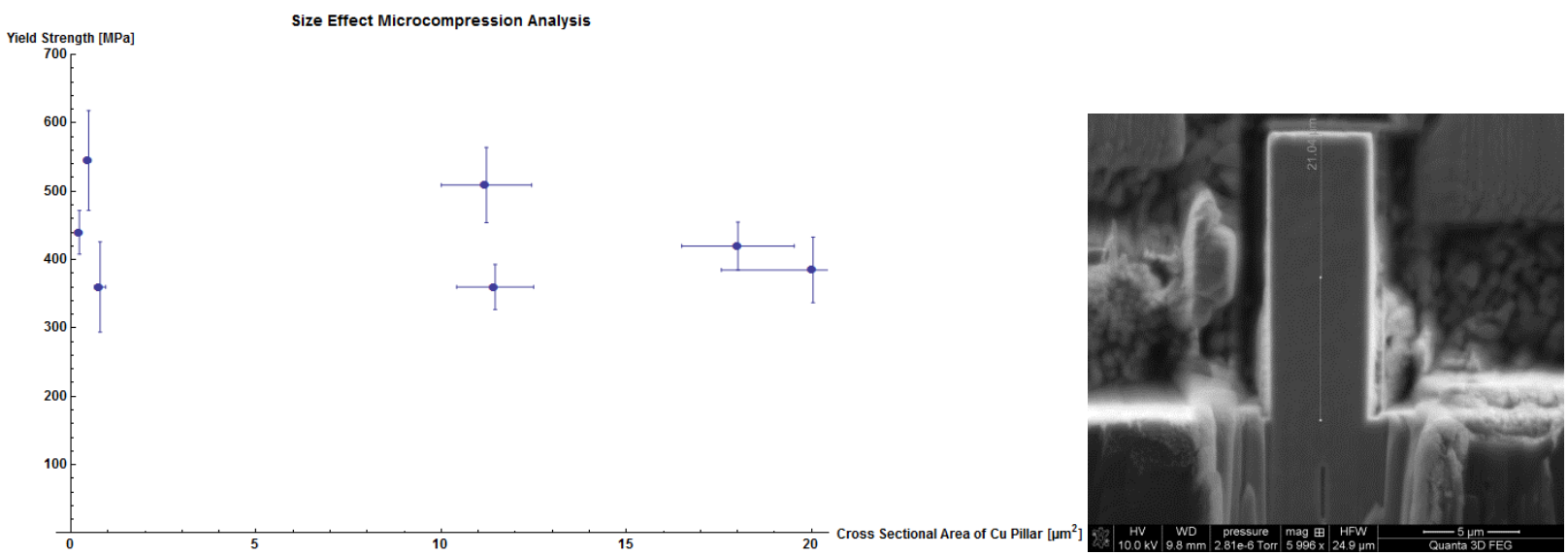

Figure 1: a) Comparison of Yield Strength for various micro pillar sizes. b) Example of a micro pillar used for in situ compression testing

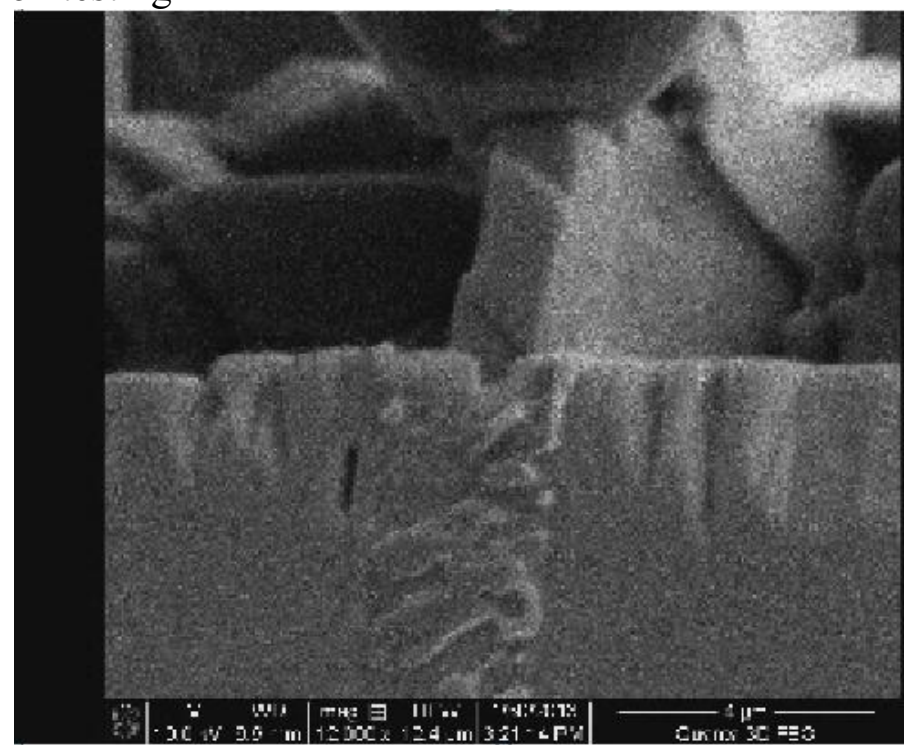

Figure 2: Frame of a movie of an in situ micro compression test of a $\mathrm{Fe} 14 \% \mathrm{Cr}$ pillar in the irradiated zone showing large sudden slip planes. 